The Journal of Laryngology \& Otology

http://journals.cambridge.org/JLO

Additional services for The Journal of Laryngology \& Otology:

Email alerts: $\underline{\text { Click here }}$

Subscriptions: $\underline{\text { Click here }}$

Commercial reprints: $\underline{\text { Click here }}$

Terms of use : $\underline{\text { Click here }}$

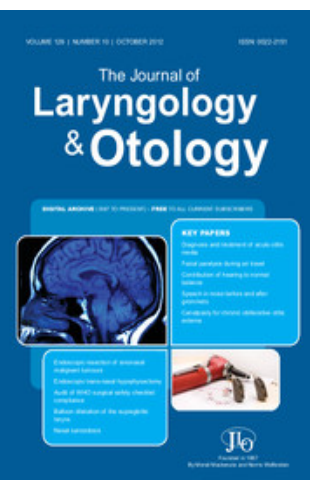

\title{
A visit to Doctor Jean-Bernard Causse, Béziers and Professor Jacques Magnan, Marseille
}

Shakeel R. Saeed

The Journal of Laryngology \& Otology / Volume 112 / Issue 01 / January 1998, pp 110 - 111

DOI: 10.1017/S0022215100140046, Published online: 29 June 2007

Link to this article: http://journals.cambridge.org/abstract_S0022215100140046

How to cite this article:

Shakeel R. Saeed (1998). A visit to Doctor Jean-Bernard Causse, Béziers and Professor Jacques Magnan, Marseille. The Journal of Laryngology \& Otology, 112, pp 110-111 doi:10.1017/S0022215100140046

Request Permissions : $\underline{\text { Click here }}$ 


\title{
JLO Travelling Fellowship 1996 Report
}

\section{A visit to Doctor Jean-Bernard Causse, Béziers and Professor Jacques Magnan, Marseille}

\author{
ShakeEl R. SAEED, F.R.C.S., F.R.C.S. (ORL) \\ Senior Registrar and Neuro-Otology Fellow, \\ University Department of Otolaryngology-Head and Neck Surgery, \\ Manchester Royal Infirmary, \\ Manchester M13 9WL.
}

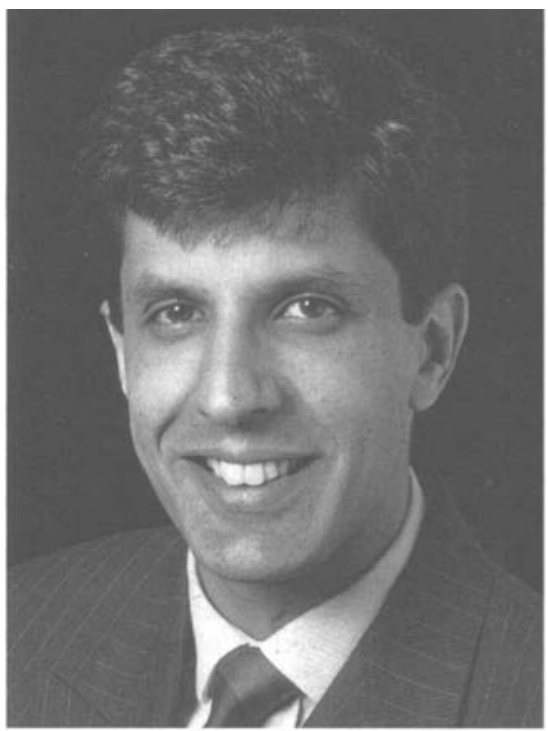

\section{Introduction}

The JLO Travelling Fellowships enable otolaryngologists in training to visit overseas centres that provide experience or expertise in areas not readily available in the UK. My own interests are in otology and neuro-otology. I therefore elected to visit two somewhat contrasting centres in the South of France: The Clinique Jean Causse which is a few kilometres from Béziers and the Service d'Oto-RhinoLaryngologie, Hôpital Nord in Marseille.

\section{Clinique Jean Causse, Béziers}

There can be few in our specialty who have not heard of the Causse Clinic. Now predominantly dedicated to surgery of the ear, the original ENT clinic was founded by Jean René Causse over 60 years ago and was situated in Béziers itself. Following a visit to John Shea in 1958, Jean René Causse imported the stapedectomy operation to France at a time when George Portmann did the same in Bordeaux. In 1975, Jean-Bernard joined his father at the Béziers clinic and three years later, having audited his son's work (no dead ears in 1000 stapedectomies), Jean René retired having undertaken over 10,000 ear procedures himself (Robinson, 1996). By 1985, a combination of two factors, the volume of work being undertaken and the financial situation that the French Health Service found itself in, necessitated a move from the Béziers site. Five years from conception to inception, the new Causse clinic is a private venture dedicated to Jean René Causse. Now situated in Colombier, $7 \mathrm{~km}$ from Béziers the clinic officially opened in 1990 .

The initial impression on visiting the clinic is one of disbelief. Set on the banks of the Midi canal, amongst rolling vineyards is a purpose built structure that looks as though it landed on this inspirational site. This surreal aura continues when you observe the work that is undertaken at the clinic: here is an institution that has taken one aspect of our specialty and developed it to a pinnacle of excellence. The clinic comprises a hotel, restaurant, library, conference room, operating theatres, audiological booths and consulting rooms in additional to the 90 ward beds. Currently there are over 20 doctors and 250 ancillary staff employed by the institution. The daily workload is remarkable: around 30 operations and up to 300 outpatient visits. Firmly at the helm of course is Jean-Bernard Causse.
As he undertakes up to five procedures per morning list I had ample opportunity to observe him operating. The whole process is highly tuned and extremely efficient. Most of the adult surgery is done under local anaesthesia with the anaesthetist administrating appropriate intravenous sedatives. The degree of sedation however is such that the patients tolerate the insertion of an oropharyngeal airway suggesting to my mind that this is a not far removed from general anaesthesia. The patient is already prepared and draped and all the personnel in the operating room are acutely aware of their precise role. Each procedure is video recorded and Jean-Bernard takes great pleasure in not only furnishing the patient with a recording of their operation but also presenting a copy to the visitors that are invariably present at each operation. With such a vast experience of middle ear surgery (over 20,000 stapedectomies), Jean-Bernard makes the actual surgery look effortless. This of course is deceptive. The various steps of the procedure are undertaken in precisely the same manner each time and there is certainly economy of movement: this in itself is a great skill that develops with experience but more importantly, when anatomical difficulties are encountered he is able to deal with them with consummate ease. It is a lesson that we can all attempt to apply to whatever aspect of otolaryngology we are involved in. The laser stapedotomy is restricted to the posterior third of the footplate, and a vein graft is utilized to make good the deficit between the $0.5 \mathrm{~mm}$ teflon prosthesis and the $0.88 \mathrm{~mm}$ stapedotomy. Jean-Bernard believes that the vein serves to emulate the function of the annular ligament of the footplate. Currently he also attempts to reconstruct the stapedial tendon mechanism by using connective tissue 'glue' from the vein graft to join the cut tendon to a polycel cuff around the neck of the prosthesis. The whole process takes about half an hour. Jean-Bernard leaves theatre to attend to administrative affairs by which time the next patient is ready for surgery: the whole thing runs like clockwork. The morning session ends with a post-operative ward round (it was interesting to meet two post-operative patients from the UK!) followed by lunch with Jean-Bernard and his colleagues in the clinic restaurant.

The Causse clinic also has a prolific throughput of surgery for chronic ear disease. This aspect is headed by Dr Benoit Gratacap, whose surgical skills reflect the ethos 
of the clinic without losing the individuality that makes every surgeon different. There is considerable emphasis on function and therefore maintenance of the posterior canal wall, reconstruction of the scutum and ossiculoplasty are considered just as important as disease exenteration. The use of the laser is certainly a useful adjunct in chronic ear surgery.

As a background to such surgical expertise lies an immense generosity of spirit. The unit is geared to a steady throughput of visitors from all over the world and all are made to feel welcome. The enthusiasm of the medical staff is striking and the hospitality unparalleled. I would implore any trainee interested in otology to visit the clinic to see how, in an appropriate environment this aspect of our specialty can be taken to great heights.

\section{Service d'Oto-Rhino-Laryngologie, Hôpital Nord in Marseille}

The Hôpital Nord is one of the University Hospitals in Marseille. Overlooking the urban sprawl of northern Marseille the hospital serves all specialties of medicine with over 700 adult beds. Its sister paediatric hospital is about a kilometre away. The service d'oto-rhino-laryngologie et chirgurie cervico faciale is headed by Professor Jacques Magnan whose interests are predominantly otology and neuro-otology. Professor Magnan has written extensively on various aspects of craniobase surgery but it is his interest in the use of rigid endoscopes in neurootology that prompted me to visit his department. My request to do so was well received and both Professor Magnan and his colleague André Chays had clearly gone to the trouble of ensuring that the operating schedule during my visit would allow me to observe the utilization of endoscopes in the posterior cranial fossa. Both Magnan and Chays hold the view that rigid endoscopes are an adjunct to the conventional techniques of posterior fossa surgery. Having observed their work, I would have to agree. The improved illumination is certainly one factor but the key difference is the manner in which the endoscope allows the surgeon to almost 'walk around' the cerebellopontine angle (CPA) and beyond. For both vestibular neurectomy and vascular decompressions the CPA is approached through a mini posterior fossa craniotomy $(2 \mathrm{~cm} \times 1 \mathrm{~cm})$ in the angle between the posterior margin of the mastoid process and a line extrapolated from the root of the zygoma. The skin and periosteal incisions are staggered and do not impinge on the musculature of the neck at the craniobase: this eliminates one of the factors supposedly implicated in the headaches frequently seen after the retrosigmoid or suboccipital approaches. The bone dust from the craniotomy is collected for use during closure and once the bone work is complete, an anteriorly based dural flap is cut exposing the posterior fossa. There is rarely a need for cerebellar retraction as hypocapnoeic anaesthesia seems to 'slacken' the field well. Using $0^{\circ}$ and $30^{\circ} 6 \mathrm{~cm} \times 4 \mathrm{~mm}$ endoscopes and television monitoring the CPA contents are visualized: the ability to see all the cranial nerves from III to XII as well as the vasculature is quite remarkable. Professor Magnan is a proponent of vascular compression syndromes and he uses the endoscopes to accurately confirm the diagnosis as well as decompress the cranial nerve in question. This exposure also allows section of the vestibular nerve utilizing the endoscope to define the plane between the cochlear and vestibular components of the eighth nerve. The indications for endoscopy in vestibular schwannoma surgery are less clear. There are instances where a $30^{\circ}$ scope will allow improved visualization of the facial nerve anterior to the tumour but more importantly, the endoscope can be used to search for remnants of tumour particularly at the lateral end if the internal auditory meatus in the retrosigmoid approach. When we do reach the goal of being able to establish the growth rate of a vestibular schwannoma from a tissue sample, then no doubt endoscopic biopsy will come into its own. Closure of the craniotomy is meticulous with suturing of the dural flap, insertion of a polyurethane (Neuro-Patch, B. Braun, Melsungen) disc that is cut to size, followed by insertion of fibrin glue-bone dust paté to make good the bony deficit. CSF leakage has not been an issue with this method and preventing adhesions between the dura and soft tissues of the scalp may be another reason why post-operative headaches are not a problem. I observed several nerve sections and vascular decompressions during the visit and I was immensely impressed. The anatomy of the CPA is varied and complex and the endoscope give an insight into this complexity that in my opinion cannot be matched by conventional microscopic means. Since my return I have had an opportunity to utilize rigid endoscopes during CPA and petrous apex surgery on several occasions and this is a technique that I shall continue to develop - being able to visualize and remove hidden matrix medial to the internal carotid artery during surgery for a petrosal cholesteatoma was certainly illuminating! Finally, as in Béziers, the hospitality in Marseille was superb. There was ample opportunity to discuss various otological issues and in particular, the newly formed European Academy of Otology and Neuro-Otology. Professor Magnan has been instrumental in getting this project off the ground and the inaugural meeting is to be held in Courchevel in February 1998. The Academy has generated support internationally and will no doubt continue to develop in years to come. Throughout my visit Professor Magnan and his team made me feel very welcome and if endoscopic CPA surgery was not enough, they had one more ace up their sleeve: the Marseille bouillabaisse was the best I have ever tasted!

Finally, I would like to express my gratitude to the $J L O$ for funding the visit to the two departments and to $\mathrm{Dr}$ Jean-Bernard Causse and Professor Jacques Magnan for their hospitality and enthusiasm to teach.

\section{References}

Robinson, J. M. (1996) The Béziers story. ENT News 5(3): 16-17. 